\title{
Oral health status, attitudes and gender variations among governmental school children at Al-Mafraq governate - Jordan
}

\author{
Leena Smadi', Lara Kharma², Asma'a Abu Abed ${ }^{3}$, Eman Bny Mfarej ${ }^{4}$, Asma Abdalmohdi ${ }^{5}$ \\ ${ }^{1}$ Professor; Faculty of Dentistry; Jordan University; Jordan \\ ${ }^{2}$ MSC Foundations in Clinical Psychology; School of Psychology; Department of Medical Sciences; Newcastle University; Jordan \\ ${ }^{3}$ Master's degree in Maternal and neonatal health; Registered nurse/midwife; Head of National Woman's Health Care Center; Jordan \\ ${ }^{4}$ Department of Statistics; Statistical Analysis Division; Jordan \\ ${ }^{5}$ RN/ Head of planning; Research and Information Department; National Woman's Health Care Center; Jordan
}

\section{Abstract}

Objectives: Calculate the prevalence and severity of dental caries and periodontal health among school students aged 12-18 years old and their attitudes toward dental health and oral hygiene at Al-Mafraq governate- Jordan.

Materials and methods: Demographic and oral behavioral information were collected; students aged 12-18 years old from six public schools distributed over three districts in Al-Mafraq governate over a sixmonth period had a full oral and dental examination. DMFT index (Decay, Missing, Filling, Teeth) was used to measure caries experience. Plaque index (PI) and gingival index (GI) of Löe and Silness were used to evaluate the oral health status. T - test was used for statistical evaluation. A P-value $<0.05$ was considered statistically significant.

Results: 1165 students were examined, $51 \%$ never had been to a dentist or had any previous dental treatment, $39.6 \%$ of the students examined never brushed their teeth and $61.85 \%$ had dental caries. The (SiC) was 4.72 with a decay representing $93.53 \%$. Females brush their teeth more frequent than males with a statistically significant difference; $p<0.001$. Females showed lower DMFT index (1.81) and compared to males (2.25) with a statistically significant difference. Females showed lower SiC (4.164) compared to males (5.186) with a statistically significant difference. There was no statistically significant difference between males and females in PI $p=0.590$, and $\mathrm{Gl} ; p=0.852$.

Conclusions: The prevalence of dental caries among students in Al-Mafraq governate and the significant caries index were substantially higher than the target goals of WHO/ FDA of year 2015 with more than
$90 \%$ of unmet treatment needs. Girls showed better oral hygiene habits compared to boys and exhibited less dental caries experience. However, periodontal status did not differ significantly between both genders.

Keywords: Dental health; oral health; adolescents; dental caries.

Citation: Smadi, L, et al. (2021) Oral health status, attitudes and gender variations among governmental schoolchildren at Al-Mafraq governate - Jordan. Dentistry 3000. 1:a001 doi:10.5195/d3000.2021.141 Received: January, 24, 2021

Accepted: March, 13, 2021

Published: September, 13, 2021

Copyright: (02021 Smadi, L, et al. This is an open access article licensed under a Creative Commons Attribution Work 4.0 United States License.

Email: alsumadi@yahoo.co.uk

\section{Introduction}

Oral health is part of the general wellbeing of an individual. [1]
Caries and periodontal disease are the two most important dental diseases, although common yet, preventable.[2] It is estimated that oral diseases affect nearly 3.5 billion people. More than 530 million children suffer from dental caries of primary teeth. Severe 
periodontal disease, which may result in tooth loss, is also very common, with almost $10 \%$ of the global population affected. [3] Oral health affects people physically and psychologically and influences how they grow, enjoy life, look, speak, chew, taste food and socialize, as well as their feelings of social well-being. [1]

Microorganisms found in dental plaque can cause dental caries and periodontal disease.[4]

Strategies that focus on increasing the awareness and motivation of the population to improve their oral hygiene, implementing prevention methods, regular check- ups and making dental care more accessible to those people in underprivileged societies can significantly decrease the prevalence of dental caries and periodontal disease.[5]

Several dental surveys have been conducted in Hashemite kingdom of Jordan but unfortunately most of them were focused in Amman capital of Jordan and examined students in private schools. $[6,7]$ The purpose of this survey and a previous survey [8-11] executed by Jordanian National Women's Health Care Center (NWHCC) and a team of researchers from the University Of Jordan, Ministry of
Health and Royal Medical Services is to identify people who are at a higher risk of developing dental caries and periodontal disease in the most needed societies in governmental schools and peripheral areas. Al-Mafraq is one of these areas located north- east of Jordan with also increasing number of Syrian refugees after Syrian political crisis in the last few years.

Our aim from this cross-sectional study was to calculate the prevalence and severity of dental caries and periodontal health among school students aged 12-18 years old and their attitudes toward dental health and oral hygiene at Al-Mafraq governateJordan.

\section{Material and Methods}

Over 6 month's period from October 2018 until March 2019, the NWHCC pre-trained teams conducted an oral health survey for students aged 12-18 years old, students were recruited from six large public schools distributed over the three main districts of AlMafraq governorate.

Ethical approval for the study was granted from the ethical committee of the Jordanian Ministry of Health (Code: MOH REC
160019). All students were examined after signing an informed consent by them and their parents. Demographic and oral behavioral data including age, gender, school, district, oral hygiene methods and previous dental treatment were recorded by using a questionnaire followed by a full oral and dental examination. The data sheet was pre-validated by experts committee of dentists and dental care nurses. A mobile dental clinic was used to examine all students at the schools; disposable examination sets (prepacked mirror and explorer) and disposable latex gloves were used during the examination.

We adopted the same methods used in our previous surveys, [8-11] to standardize the examination procedures and to decrease differences in examination outcome, three general practitioner dentists who conducted the clinical examination attended a training course before starting the survey. Pre-survey assessment of agreement was performed between examiners, with Kappa inter-examiner of 0.93 and intra- examiner of 0.98 .

Tooth decay was defined according to WHO criteria as 'cavities with a softened dentine floor', we had 
previously used this definition in a previous study. [8] The number of teeth with untreated decay (cavity) was defined as DT (decayed teeth), the number of teeth with decay in the past that had been repaired by operative procedures were defined as FT (filled teeth), and MT (missing teeth) was used to describe teeth removed or extracted because of decay. The sum of DT, MT and FT which represented the total number of teeth affected by tooth decay was referred to as the DMFT. The level of tooth decay in a population can be represented by the mean values of DT, MT, FT and DMFT as well as by the proportion of the population affected by each type of decay. The DMFT ratio represents the total number of teeth affected in the past and present, this value is a cohort that is more representative of the oral health status than the DT, which indicates those teeth requiring attention because of untreated decay; therefore we chose DMFT for evaluation and reporting in this study, although this index can be criticized for not counting either enamel caries, or caries activity, or even teeth or surfaces at special risk, in addition to not confirming the reason for decay extraction during examination, especially for deciduous teeth. However, it is good in providing descriptive information for trends monitoring and policy makers' awareness of dental health. Significant caries index ( $\mathrm{SiC}$ ) was used in this survey to overcome the limitation in the distribution of DMFT. The (SiC) refers to the one-third of the population that are more severely affected by dental caries.[12]

Oral plaque was evaluated by running the side of a ball-tip probe along the inner and outer aspects of the six index teeth, using the criteria of the plaque index of Silness and Löe. [13] The six indexed teeth are the upper right first molar, upper right lateral incisor, upper left first premolar, lower right first premolar, lower left lateral incisor and first molar. Missing teeth are not substituted. The gingival condition was determined for the same teeth using the criteria of the gingival index of Löe and Silness. [13]

Objective research was performed to evaluate the state of oral hygiene during the examination as follows: good (plaque index 0.0 i.e., absence of plaque), fair (plaque index 0.1-1.9 i.e., presence of plaque) and bad (plaque index 2.03.0 i.e., plaque seen by the naked eye). The gingival index of Löe and Silness was used to record the severity of gingivitis. The gingival index by Löe and Silness measures the severity of gingivitis on a scale ranging from 0.1-3.0 (0.1-1.0: mild gingivitis, 1.1-2.0: moderate gingivitis, and 2.1-3.0: severe gingivitis).

Statistical analysis was performed using SPSS for Windows (version 20, IBM Corporation, Armonk, NY). The $T$ - test was used for statistical evaluation. A P-value $<0.05$ was considered statistically significant.

\section{Results}

1165 students were examined $48.4 \%$ were males $51.6 \%$ were females, age range from 11 to 18 approximately half were in age group from 13 to 15 years old. $94.1 \%$ were Jordanian and the rest were Syrian refugees. Nearly half of the students examined (51\%) never had been to a dentist or had any previous dental treatment.

\section{Oral hygiene habits:}

More than third of the students examined never brushed their teeth (39.6\%) with approximately the same percentage brushed their teeth once daily. Teeth brushing was the only oral hygiene method in $87.7 \%$ of the students examined, only $0.4 \%$ claimed to use dental floss, $0.7 \%$ used toothpicks whereas $11.4 \%$ used mouthwash. 


\section{Dentistry $300 \square$ \\ Vol 9 No 1 (2021) DOI 10.5195/d3000.2021.141}

Caries prevalence and caries Index:

Out of 1165 students examined only $38.15 \%$ were caries free (61.85\% have caries). DMFT index was found to be 2.037 with a decay representing $92.8 \%$, Missing $2.22 \%$ and fillings $5.58 \%$. One third of the students examined were found to have DMFT index 4.723 (significant caries index $\mathrm{SiC}$ ) with a decay representing 93.53\%, Missing $1.62 \%$ and fillings $4.83 \%$. (Table 1 )

Table 1: DMFT index, Significant caries index and percentile of $D, M, F$.

\begin{tabular}{|l|l|l|l|}
\hline \multicolumn{2}{|c|}{$\begin{array}{c}\text { DMFT } \\
\text { index=2.037 }\end{array}$} & \multicolumn{2}{c|}{ SiC $=4.723$} \\
\hline$\% \mathrm{D}$ & 92.18 & $\% \mathrm{D}$ & 93.53 \\
\hline$\% \mathrm{M}$ & 2.22 & $\% \mathrm{M}$ & 1.62 \\
\hline$\% \mathrm{~F}$ & 5.58 & $\% \mathrm{~F}$ & 4.83 \\
\hline
\end{tabular}

\section{Plaque index and gingival index:}

Plaque index (PI) was found to be $0.422 \pm$ SD 0.5991 whereas gingival index was found to be $0.361 \pm S D$ 0.585. According to $\mathrm{PI}$ approximately two thirds (63.2\%) were classified as having good oral hygiene $(\mathrm{PI}=0.0)$, approximately one third (31.8\%) were classified as having Fair oral hygiene $(\mathrm{PI}=0.1$ $1.9)$ and only $5 \%$ were classified as having poor oral hygiene $(\mathrm{PI}=2.0$ 3.0).

According to $\mathrm{Gl} 69.1 \%$ were classified as having healthy gingiva $(\mathrm{Gl}=0.0)$, approximately a quarter (26\%) were classified as having mild gingivitis ( $\mathrm{Gl}=0.1-1.0$ ) less than $5 \%(4.5 \%)$ were classified as having moderate gingivitis ( $\mathrm{Gl}=1.1$ $2.0)$ and less than $1 \%(0.30 \%)$ were classified as having severe gingivitis. (Table 2)

\section{Gender variations}

Table 3 shows gender variations according to the following

\section{Frequency of teeth brushing and gender}

There was a statistically significant difference between males ( $M=$ $0.68, S D=0.76)$ and females $(M=$ $1.03, S D=0.89$ ) in frequency of teeth brushing; $\mathrm{t}(1166)=-7.233$, $p=0.000$

\section{Caries index and gender:}

DMFT index was 2.254 for males whereas it was 1.814 for females, independent samples t-test showed that there was a statistically significant difference between males ( $M=$ 2.25, $S D=2.51$ ) and females $(\mathrm{M}=1.83, \mathrm{SD}=2.17)$ in $\mathrm{DMF}$ scores; $t(1168)=3.068 p=$ 0.002

Significant caries index was 5.186 for males whereas it was 4.164 for females independent samples ttest showed that there was a statistically significant difference between males $(M=3.46, S D=2.34)$ and females $(\mathrm{M}=2.32, \mathrm{SD}=2.20)$ in significant Caries Index scores; t $(845)=7.278 p=0.000$.

\section{3. $\mathrm{PI}, \mathrm{Gl}$ and gender}

There was no statistically significant difference between males $(M=0.432, S D=0.57)$ and females $(M=0.423, S D=0.63)$ in plaque Index scores; $t$ (1166) = $0.539 p=0.590$

There was no significant difference between males ( $M=0.37, S D=0.53$ ) and females $(M=0.36, S D=0.63)$ in gingival Index scores; t $(1166)=$ $0.187 p=0.852$ 
Table 2: Percentile of school students according to gingival status:

\begin{tabular}{|l|l|l|}
\hline GI & Gingival status & Percentage $\%$ \\
\hline 0.0 & Healthy gingiva & $69.1 \%$ \\
\hline $0.1-1.0$ & Mild gingivitis & $26 \%$ \\
\hline $1.1-2.0$ & Moderate gingivitis & $4.5 \%$ \\
\hline $2.1-3.0$ & Severe gingivitis & $0.30 \%$ \\
\hline
\end{tabular}

Table 3: Gender variations (Independent samples t-test):

\begin{tabular}{|l|l|l|l|}
\hline & Males & Females & $\mathrm{P}$ value \\
\hline Number & 565 & 603 & \\
\hline $\mathrm{D}+\mathrm{M}+\mathrm{F}$ & 1274 & 1094 & \\
\hline DMFT index & $2.254 \pm 2.51$ & $1.814 \pm 2.17$ & $\mathrm{P}=002 *$ \\
\hline SiC & $5.186 \pm 2.34$ & $4.164 \pm 2.2$ & $\mathrm{P}<001 *$ \\
\hline $\mathrm{PI}$ & $0.432 \pm 0.57$ & $0.432 \pm 0.63$ & $\mathrm{P}=0.590$ \\
\hline GI & $0.37 \pm 0.53$ & $0.36 \pm 0.63$ & $\mathrm{P}=0.852$ \\
\hline $\begin{array}{l}\text { Frequency of teeth } \\
\text { brushing }\end{array}$ & $0.68 \pm 0.76$ & $1.03 \pm 0.89$ & $\mathrm{P}<001 *$ \\
\hline
\end{tabular}

* P value shows statistically significant difference

\section{Discussion}

The results of this study showed that more than half of the students examined lack any dental care, more than one third of those students never brushed their teeth and almost all of them never used dental floss, this may be explained by poor income, unavailability of dental clinics and unavailability of dental health insurance on one side and lack of motivation, knowledge and dental education on the other side.[14]

The prevalence of caries in those students was very high $(61.85 \%)$, the significant caries index was also high (4.723) with $93.53 \%$ have been left untreated and only $4.83 \%$ received dental fillings or have been extracted (1.62\%). The high prevalence and severity of dental caries with the unmet treatment needs were consistent with other previous studies. [6-11]

the observed prevalence of dental caries among student in the present study was higher than the target established for the year 2000 (50\%) by WHO/FDI [15], also the significant caries index was higher than a global oral health goal for significant caries index of less than 3 DMFT in the 12-year-olds in a given population by the year 2015.[12]

The results of this survey and previous surveys [8-11] indicate the need for dental education, and motivation for proper oral hygiene methods and to implement dental preventive and treatment methods which may include water fluoridation of drinking water for school children [16]and to provide governmental dental insurance for school children, needless to mention that poor oral status may put future extra burden on the government because of the need for more complicated and expensive dental treatment like for example root canal treatment, fixed or removable prostheses or implants for replacement of missing teeth in addition to the psychological impact of losing teeth on an individual .[17]

Although $63.2 \%$ were classified as having good oral hygiene according to $\mathrm{Pl}$, the remains of the students were classified as having poor to fair oral hygiene, similarly approximately one third of those students 
were classified as having mild, moderate to severe gingivitis

which emphasizes the need for dental education for both parents, teachers and students and may be supervised teeth brushing and flossing session [18]

Obviously, this study shows that females had more positive behavior than males concerning teeth brushing their teeth than males, this is consistent with a previous meta-analysis of 1981, 2000, and 2010 data of Greek students by gender which showed that females brushed their teeth significantly more often than males [19]

The difference could be attributed to the fact that the society puts more pressure on girls to improve their image or girls tend to be more protective on themselves in a society which is still male driven particularly in areas of poor socioeconomic status. This positive oral hygiene behavior reflected on less caries index in girls than boys with a statistically significant difference, nevertheless it did not reflect on gingival status in this study where there was no statistically significant difference between boys and girls, this may be explained by be hormonal differences between boys and girls at this age and its effect on periodontal status. [20]

Although the present study is not based on a representative sample of public-school children in AlMafraq governate because it uses convenience sampling, it does provide insight into the prevalence and severity of caries and gingivitis and lack of oral hygiene practice and dental care among public school children. The results of this survey indicate the need to start a local campaign to raise the public awareness of oral hygiene and the need to modify policies for early access to dental services among school children.

\section{Conclusions}

The prevalence of dental caries among students in Al-Mafraq governate and the significant caries index were substantially higher than the target goals of WHO/ FDA of year 2015 with more than $90 \%$ of unmet treatment needs. Girls showed better oral hygiene habits compared to boys and exhibited less dental caries experience. However, periodontal status did not differ significantly between both genders.

\section{Acknowledgements}

The authors would like to thank the National Woman's Health Care Center-Jordan who organized and executed this survey in collaboration with Jordanian Ministry of health, Jordanian Ministry of Education and Jordanian Royal Medical Services who used their resources and staff to conduct the survey and for their effort to make the data of this survey available for research and publication.

\section{Competing interests}

The authors declare that they have no competing interests.

\section{References}

1. Peck C.C. (2017) Putting the Mouth into Health: The Importance of Oral Health for General Health. In: Sasaki K., Suzuki O., Takahashi N. (eds) Interface Oral Health Science 2016. Springer, Singapore. https://doi.org/10.1007/97 8-981-10-1560-1_7

2. Oral health: the silent epidemic Benjamin RM.. Public Health Rep. 2010;125(2):158-159. doi:10.1177/00333549101 2500202 
Oral health status, attitudes and gender variations among governmental schoolchildren at Al-Mafraq governate - Jordan

3. Global, regional, and national incidence, prevalence, and years lived with disability for 354 diseases and injuries for 195 countries and territories, 1990-2017: a systematic analysis for the Global Burden of Disease Study 2017. Lancet 2018; 392: 1789-8583

4. Caries and Periodontitis: Contesting the Conventional Wisdom on Their Aetiology. Manji F, Dahlen G, Fejerskov O: Caries Res 2018; 52:548564. doi: $10.1159 / 000488948$

5. Strategies and approaches in oral disease prevention and health promotion.Watt, Richard. (2005). Bulletin of the World Health Organisation. 83. 711-718.

6. Caries in preschool children in Amman, Jordan and the relationship to sociodemographic factors. Sayegh, A \& Dini, E.L. \& Holt, R.D. \& Bedi, Raman. (2002). International dental journal. $52 . \quad 87-93$. 10.1111/j.1875595X.2002.tb00606. x.

7. Early childhood caries and risk factors in Jordan.
Community Dent

Health.Rajab LD, Hamdan

MA. 2002 Dec;19(4):224-9.

PMID: 12489836.

8. Prevalence and Severity of Dental Caries in school students aged 6 - 11 years in Tafelah Governorate South Jordan: Results of National Woman's Health Care Center Survey. Smadi I, Azab R, Rodan R, Khlaifat F, Abdalmohdi A. OHDM. 2015; 14: 17-22.

9. Prevalence and severity of gingivitis in school students aged 6-11 years in Tafelah Governorate, South Jordan: results of the survey executed by National Woman's Health Care Center. Rodan R, Khlaifat F, Smadi L, Azab $\mathrm{R}$, Abdalmohdi A. BMC Res Notes. 2015 Nov 9; 8:662.

10. Prevalence and severity of dental caries in school students aged $6-12$ years in Mafraq governorate: Northeast of Jordan.Smadi L, Azab R, Khlaifat F, Rodan R, Abdalmohdi A, Maata R, et al. J Oral Health Oral Epidemiol 2017; 6(1): 40-7.

11. Oral health status and behaviors in Jordanian adolescents aged 12-18 years. Smadi L. AMJ 2017;10 (7):587-594.

12. Introducing the Significant Caries Index together with a proposal for a new global oral health goal for 12-yearolds. Bratthall D. Int Dent J 2000; 50(6): 378-84.

13. Socio-economic inequality in oral healthcare coverage: results from the World Health Survey. Hosseinpoor AR, Itani L, Petersen PE. J Dent Res. 2012;91(3):275-281.

14. The Gingival Index, the Plaque Index and the Retention Index Systems. J Periodontol Löe H.. 1967 Nov-Dec;38(6): Suppl:6106. doi: 10.1902/jop.1967.38.6.610 . PMID: 5237684.

15. Challenges to improvement of oral health in the 21st century--the approach of the WHO Global Oral Health Programme Petersen PE.. Int Dent J. 2004 Dec;54(6 Suppl 1):329-43. doi: 10.1111/j.1875595x.2004.tb00009. x. PMID: 15631094.

16. Effectiveness of school water fluoridation and dietary fluoride supplements in school- 


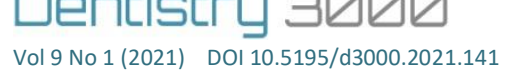

aged children. Horowitz HS.

$J$ Public Health Dent. 1989;49(5 Spec No):290-6.

doi: $10.1111 /$ j.1752-7325. 1989.tb02087. x. PMID: 2681731.

17. Oral diseases: a global public health challenge. Peres MA Macpherson LMD Weyant RJ et al. Lancet. 2019; 394: 249260.

18. Effectiveness of supervised toothbrushing and oral health education in improving oral hygiene status and practices of urban and rural school children: A comparative study. Damle SG, Patil A, Jain S, Damle D, Chopal N. J Int Soc Prev Community Dent. 2014 Sep;4(3):17581. doi: 10.4103/22310762.142021. PMID: 25374836; PMCID: PMC4209617.

19. Gender differences in oral health status and behavior of Greek dental students: A meta-analysis of 1981, 2000, and 2010 data. Mamai-Homata E, KoletsiKounari H, Margaritis V. J Int Soc Prev Community Dent. 2016 Jan-Feb;6(1):608. doi: 10.4103/22310762.175411. PMID:
27011935; PMCID:

PMC4784066.

20. Effects of endogenous sex hormones on the periodontium--review of literature. Güncü GN, Tözüm TF, Cağlayan F. Aust Dent J. 2005 Sep;50(3):13845. doi: 10.1111/j.18347819. 2005.tb00352. $x$. PMID: 16238210. 